\title{
The role of flavonoids in the prevention and management of cardiovascular complications: a narrative review
}

\author{
Zhao Chen ${ }^{1}$, Shi-Liang Zhang $^{2}$ \\ ${ }^{1}$ College of Chinese Medicine, Shandong University of Traditional Chinese Medicine, Jinan, China; ${ }^{2}$ Section 4, Department of Cardiology, The \\ Affiliated Hospital of Shandong University of Traditional Chinese Medicine, Jinan, China \\ Contributions: (I) Conception and design: Z Chen; (II) Administrative support: SL Zhang; (III) Provision of study materials or patients: Both authors; \\ (IV) Collection and assembly of data: Both authors; (V) Data analysis and interpretation: Both authors; (VI) Manuscript writing: Both authors; (VII) \\ Final approval of manuscript: Both authors. \\ Correspondence to: Dr. Shi-Liang Zhang, MD. Section 4, Department of Cardiology, The Affiliated Hospital of Shandong University of Traditional \\ Chinese Medicine, No. 42, Wenhua West Road, Jinan 250011, China. Email: zhangshiliangsd@163.com.
}

Objective: Cardiovascular diseases (CVDs) are the world's leading cause of death, affecting an estimated 17.9 million people. CVDs have been the primary risk factor for mortality in developed countries. Smoking, hypertension, diabetes, abdominal obesity, psychological stressors, insufficient vegetable and fruit intake could significantly alleviate the burden of disease. The present review sought to document the antihypertensive, anti-arrhythmic, anti-anginal, and anti-infarction effects of flavonoids.

Background Cardiovascular disorders are the leading cause of death worldwide, affecting an estimated 17.9 million individuals. Strokes and heart attacks account for 4 out of every 5 deaths caused by cardiovascular disorders. Physical activity protects against a variety of chronic conditions at any age. A demographic program combined with a high-risk CVD prevention approach could dramatically minimize the disease burden in the coming years. By controlling weight and improving the body's use of insulin, physical activity decreases the risk of CVDs. Tobacco and smoking are other modifiable factors associated with the progression of cardiovascular disorders. Abnormal blood lipids are also linked to dietary habits. Daily flavonoid consumption is linked to a lower risk of heart disease. Flavonoids have been the subject of significant interest by experts in recent times due to wide spectrum of possible benefits they provide. polyphenolic compounds can be useful as adjunctive therapy for the management and cure of inflammatory diseases.

Methods: Literature related to cardiovascular effects of flavonoids was assessed on important database like PubMed, Scopus, ScienceDirect. The outcomes of various studies were documented.

Conclusions: Flavonoids are fairly soluble in physiological media and thus are a potential candidate for the possible management of cardiovascular and associated disorders. Alleviating the oxidative stress induced by reactive oxygen species using anti-oxidant-rich flavonoids could lower the chances of platelet hyperactivation, heart disease, discomfort, and fibrosis. Flavonoid intake on a daily basis has been linked to a lower risk of heart failure. Polyphenolic compounds have the ability to be used as an adjunctive therapy in the prevention and control of cardiovascular and inflammatory diseases. Flavonoids have a role in the management of coagulation disorders.

Keywords: Flavonoids; anti-hypertensive; anti-arrhythmic; anti-anginal; coagulation disorders

Submitted Apr 22, 2021. Accepted for publication Jun 24, 2021.

doi: 10.21037/apm-21-1343

View this article at: https://dx.doi.org/10.21037/apm-21-1343 


\section{Introduction}

Cardiovascular diseases (CVDs) are the world's leading cause of death, affecting an estimated 17.9 million people around the world (1). For the last few decades, CVDs have been the primary risk factor for mortality in developed countries, and developing countries are quickly catching up (2). The underlying pathology of atherosclerotic vascular disease results in coronary artery disease, cerebrovascular disease, peripheral vascular disease, and the subsequent development of cardiac arrhythmias. The main health issues for these conditions have been identified, and include elevated levels of low-density lipoprotein (LDL) cholesterol, smoking, hypertension, diabetes, abdominal obesity, psychological stressors, insufficient vegetable and fruit intake, excessive drinking, and a lack of regular physical activity (3). CVDs include coronary heart disease, cerebrovascular disease, rheumatic heart disease, and other complications. Four out of 5 deaths are observed which are associated with cardiovascular problems and are due to strokes and heart attacks (4). The risk factors are configurable; however, to date, the prevention or control measures, especially in developing countries, have been lacking. In the coming years, a population policy paired with a high-risk CVD prevention strategy could significantly alleviate the burden of disease $(5,6)$. We present the following article in accordance with the Narrative Review reporting checklist (available at https://dx.doi.org/10.21037/ apm-21-1343).

\section{Methods}

\section{Risk factors}

The world's growing urbanization and industrialization have reduced people's physical activity levels. Physical activity protects against a variety of chronic conditions at any age. By controlling weight and improving the body's use of insulin, physical activity decreases the risk of CVDs (7). Tobacco and smoking are other modifiable factors associated with the progression of cardiovascular disorders. Tobacco smoke affects the endothelium, stimulates arterial fat deposits, enhances clotting, tends to increase LDL cholesterol and decrease high-density lipoprotein (HDL) cholesterol, and promotes coronary artery spasticity (8). There is a clear association between abnormal blood lipid concentrations and the likelihood of coronary artery disease, cardiac arrest, and cardiovascular failure. Abnormal blood lipids are also linked to dietary habits. A diet rich in saturated fats and trans fats contributes to high cholesterol levels $(9,10)$.

Alcohol use has been observed to affect the cardiac muscle and raise the risk of stroke and cardiac arrhythmia. Other complications associated with drinking too much alcohol include high blood pressure, acute myocardial infarction, cardiomyopathy, liver cirrhosis, aggression, and suicide $(11,12)$. Obesity is one of several significant risk factors for CVD as well as other hormonal disorders, such as diabetes. As shown by the rising rate of obesity, the general human population is becoming overweight. There are approximately 400 million adults globally who are obese and 1 billion who are overweight and suffer from the risk of CVDs (13).

\section{Flavonoids}

Reactive oxygen species are reactive molecules that are continuously formed in organisms by enzymatic reactions (14). Under normal conditions, reactive oxygen species are generated at lower concentrations than those needed for normal cell activity, and the body's intrinsic anti-oxidant protection mechanisms are capable of minimizing any harmful effects (15). However, many proven health issues related to heart disease are being attributed to an increase in reactive oxygen species production, a condition called oxidative stress (16). Numerous epidemiological trials have found that daily flavonoid consumption is linked to a lower risk of heart disease (17). Flavonoids area type of natural product with a polyphenolic structure and basic components that consist of 3 heterocyclic rings ( 2 phenyl rings and a heterocyclic ring). These 3 elements combine to form the flava kernel, which is the central component of flavonoids (18). Flavonoids have been the subject of significant interest by experts in recent times due to the wide spectrum of possible benefits they provide. Owing to the variability of the molecular structures, complicated long-term research, and several reports have indicated that polyphenolic compounds can be useful as an adjunctive therapy for the management and cure of inflammatory diseases (19).

\section{Discussion}

\section{The role of flavonoids in the management of hypertension}

Flavonoids, a class of natural products with complex phenolic structures, are present in berries, herbs, nuts, wood, roots, branches, bulbs, coffee, and tea. The 
beneficial health effects of these natural substances are well recognized. Flavonoids are also known to be an essential ingredient in a multitude of pharmaceutical, nutraceutical, medical, and cosmetic products. This is due to their antioxidant, anti-inflammatory, anti-mutagenic, and anticarcinogenic effects, and their ability to modulate crucial cellular enzyme activity (20). Rutin and quercetin are reported to regulate and restore elevated blood pressure and promote the anti-oxidant defense system. In one study, rats fed an $8 \%$ sodium chloride-supplemented diet (i.e., a high-salt diet) for 12 fortnights showed an increase in systolic, diastolic, pulse, and mean arterial blood pressures. Lipid peroxidation was increased and the anti-oxidant enzymes were down regulated. Treatment with rutin and quercetin for nearly 2 weeks resulted in notable reversals of these indices compared to the animals fed only the highsalt diet (the without treatment group). The high-salt diet also resulted in noteworthy increments in the serum urea, creatinine, glucose, triglycerides, low-density-lipoprotein, and total cholesterol levels. The administration of rutin and quercetin retarded the effects of the high-salt diet for these biochemical indices. The reference drug, nifedipine, was found to be less effective than rutin and quercetin. The outcomes of the study indicate the roles of rutin and quercetin as anti-hypertensive agents and anti-oxidants (21). The administration of rutin resulted in the restoration of baroreflex sensitivity in 2-kidney-1clip rats. The cardiac contractility was also decreased, and vasorelaxation tended to be restored. The rutin treatment also resulted in a decrement in lipid peroxidation (22). In another independent study that used the 2-kidney-1-clip model, the administration of rutin restored systolic and diastolic blood pressure. The restoration of glutathione and plasma renin was observed to be dose dependent (23). In a clinical study, the administration of quercetin was found to result in a decrement in hypertension in stage 1 hypertensive patients, including reductions in systolic, diastolic, and mean arterial pressures (24).

The anti-hypertensive effects of catechin and its derivatives are widely acknowledged. Tea, specifically green tea, is an important source of catechin. Tea is widely consumed worldwide (25), and contains antioxidants that have been proven to be beneficial to health. Catechin constitutes about $3 \%$ of green tea $(25,26)$. Numerous studies have reported that the consumption of green tea has beneficial effects on hypertension. Indeed, the administration of catechin-rich green tea has been shown to result in a decrement in systolic and diastolic blood pressure. The lipid profile was restored to normal levels. The decrement in LDL cholesterol is prominent. Alterations in blood glucose levels due to normotension appear to be significant (27). Catechin-rich oil has been reported to have an anti-hypertensive effect, as it upregulates nitric oxide (NO) levels. Research has shown a notable decrease in the wall-to-lumen ratio to near normal values under NO deficiency (28). Benifuuki tea is a popular green tea consumed in Japan. It is a rich source of (-)-epigallocatechin-3-O-(3-O-methyl) gallate. This polyphenol has a significant effect on the inhibition of the angiotensin I-converting enzyme. Benifuuki tea has also been shown to have an anti-hypertensive effect, especially on systolic pressure (29).

Oranges are one of the richest sources of hesperidin. Hesperidin is one of the major anti-oxidant flavonoids (30). In a preclinical study, the anti-hypertensive effects of glucosyl hesperidin and hesperetin were evaluated in animal models (spontaneously hypertensive rats and normotensive Wistar-Kyoto rats). The administration of glucosyl hesperidin (doses of 10 to $50 \mathrm{mg} / \mathrm{kg}$ ) to the experimental animals resulted in a dose-associated decrement in systolic blood pressure; however, no notable effect was observed in the normotensive animals. Similarly, the intraperitoneal administration of hesperitin to spontaneous hypertensive rats resulted in a notable decrement in systolic blood pressure. Such a response was associated with the inhibition of NO synthase. The effect was observed due to NOmediated vasodilation (31). The possible anti-hypertensive effects of hesperidin have been studied in type- 2 diabetes patients. In a clinical study, patients were administered a 500-mg hesperidin capsule every day for 6 days. The placebo group received a starch filler capsule. Systolic and diastolic blood pressure were taken into consideration when determining the blood pressure of the patients. Patients' systolic and diastolic blood pressure was restored to normal at the end of the protocol. The levels of tumor necrosis factor-(TNF)- $\alpha$ and interleukin (IL)- 6 were notably decreased in the hesperidin treated group. An increase in total anti-oxidant capacity was also observed. This effect may be due to one of the metabolites of hesperidin; that is, hesperetin-O-glucuronide. The metabolite is associated with endothelium-dependent vasodilation and the suppression of inflammation of endothelial cells (31). The pharmacological effects of the administration of hesperidin and glucosyl hesperidin along with naringin were evaluated in stroke-prone spontaneously hypertensive rats. The study showed that the administration of these flavonoids resulted 
Table 1 Anti-hypertensive mechanism of flavonoids

\begin{tabular}{ll}
\hline Flavonoid & Mechanism \\
\hline Scopoletin & Angiotensin II receptor antagonism (38) \\
Quercetin & Inhibition of angiotensin converting enzyme (39) \\
Daidzein & Endothelial-independent vasodilation (40) \\
Taxifolin & $\begin{array}{l}\text { Angiotensin converting enzyme inhibition in the } \\
\text { aorta (41) }\end{array}$ \\
Fisetin & Downregulation of matrix metalloproteinase-9 (41) \\
Theaflavins & $\begin{array}{l}\text { Prevention of LDL oxidation (42) } \\
\text { Catechin }\end{array}$ \\
Pelphinidin & $\begin{array}{l}\text { Obstruction of the angiotensin converting } \\
\text { enzyme (39) }\end{array}$ \\
Petunidin & Phospholipase A2 inhibitor (43) \\
\hline
\end{tabular}

LDL, low-density lipoprotein.

in the restoration of blood pressure and a decrement in thrombolytic tendency. The biosynthesis of $\mathrm{NO}$ was also increased. Further, the endothelial function was restored due to the administration of these natural flavonoids (31).

Genistein is another documented isoflavone present in various soybeans and soy products. Genistein has been the subject of considerable interest by the biomedical community due to its apparent positive effects on major human illnesses, such as cancer. Mechanistically, genistein has a propensity for apoptotic activation, arresting the cell cycle, and also has anti-angiogenic, anti-cancer, and antiapoptotic effects. Genistein has a tendency to regulate NO biosynthesis. Specifically, it increases the expression of NO. It also increases aortic wall thickness and decreases hypertension (32). In high-sodium chloride $(\mathrm{NaCl})$ diet-fed rats, the administration of genistein blunted hypertension. Studies also suggest that it has anti-hypertensive effects associated with the autonomic nervous system. Genistein has also been observed to decrease insulin resistance and restore triglycerides' (33). The key mechanism by which genistein mediates cardiovascular function is via its association with estrogen receptors. Genistein is capable of binding to the estrogen-receptor beta $(\operatorname{Er} \beta)$ and activating ER-dependent gene transcription. Genistein also greatly affects the protein expression implicated in vascular tone control; that is, the atrial natriuretic peptide receptor, endothelin converting enzyme 1, angiotensin converting enzyme, atrial natriuretic peptide receptor, and endothelial NO synthase $(34,35)$. Erythropoietin and its receptor play a defensive role in the prevention of pulmonary hypertension. In one study, the administration of genistein in hypobaric conditions prevented vascular remodeling and pulmonary hemodynamics. Vasodilation associated with phosphatidylinositol 3-kinase and NO was also observed (36).

Due to the rise in hypoxia-inducible factor (HIF)- $1 \alpha$, hypertension-induced myocardial injury is often followed by impaired myocardial glucolipid metabolism. The potential benefits of apigenin for hypertension have been studied. Research has shown that the administration of apigenin resulted in a decrement in blood pressure and restored heart weight and serum angiotensin II. Additionally, apigenin administration resulted in a decrement in the expression of carnitine palmitoyltransferase-1, peroxisome proliferatoractivated receptor- $\alpha$, glycerol-3-phosphate acyltransferase genes, and glucose transporter-4 proteins. It has been suggested that apigenin may have beneficial effects in hypertensive cardiac hypertrophy (37). Table 1 details the effects of other flavonoids on hypertension.

\section{The role of anti-oxidants in the management of cardiac arrhythmia}

Arrhythmia refers to a diverse variety of disorders associated with abnormalities in heart rate and rhythm. Based on heart rate, arrhythmias are classified as bradyarrhythmias or tachyarrhythmias. They are also classified based on their origin, mode of propagation, and the syndromes with which they are associated. Patients with arrhythmias can present with a wide range of clinical symptoms, ranging from being completely asymptomatic to sudden cardiac arrest. As arrhythmias can be paroxysmal, assessing their exact prevalence is challenging. The event of cardiac arrhythmia addresses the diagnosis and management of multiple arrhythmias, and also the involvement of multidisciplinary teams in the care of such cases.

Quercetin has been observed to have anti-ischemic and anti-arrhythmic effects, and has a beneficial role in the homeostasis of patients with ischemic heart disease (44). The administration of quercetin $(120 \mathrm{mg} /$ day orally) for a period of 2 months resulted in the restoration of the ejection fraction and left ventricular systolic function (45). A total decrement in the depression of ST segment depression was also observed due to quercetin administration (45). The Ganshanbian herb is used in the treatment of cardiac arrhythmias. In one study, the flavonoid-rich fraction of Ganshanbian was isolated and evaluated to examine its anti- 
arrhythmic effects in an animal model. The administration of the flavonoid-rich fraction to the animals resulted in an increase in the appearance time and a decrease in the duration of ischemia and heartbeat. There was an increase in the expression of cell membrane associated messenger ribonucleic acid (mRNA) of L-calcium channels $\alpha$ type $\mathrm{Ca}_{\mathrm{L}-\mathrm{al} \mathrm{C}}$. The expression of $\mathrm{K}^{+}$channel pore-forming subunit Kir6.1 ( $\mathrm{K}_{\mathrm{ATP}}$-Kir6.1) mRNA was enhanced in myocardial cells. Treatment resulted in the restriction of calcium $\left(\mathrm{Ca}^{2+}\right)$ ion inflow and the regulation of the concentration of $\mathrm{Ca}^{2+}$ ion myocardial cells by inhibiting the time in which the L-type $\mathrm{Ca}^{2+}$ channels opened (46).

The potential anti-arrhythmic effects of flavonoids from the Chinese medicine Viscum coloratum have also been evaluated. The administration of $0.1 \mathrm{mg} / \mathrm{mL}$ of a flavonoid-rich extract of Viscum coloratum facilitated steps 2 and 3 in the repolarization of the fast response action and reduced the length of the action potential (47). In another study, the administration of the flavonoid-rich fraction of Viscum coloratum shortened the action potential and led to a decrement in the arrhythmia index. This effect was mediated by virtue of the inhibition of L-type $\mathrm{Ca}^{2+}$ currents (48).

According to epidemiological studies, the intake and consumption of green tea and cardiovascular health are positively associated. Green tea comprises flavonoids and polyphenols that tend to demonstrate anti-oxidant and anti-hypertensive effects, which contribute to lower cardiovascular mortality (49). Epigallocatechin-3-Gallate, a polyphenol, is one of the important components of green tea. The supplementation of Epigallocatechin-3-Gallate resulted in the increased survival of myocytes (50). In low concentrations, Epigallocatechin-3-Gallate facilitated the $\mathrm{Na}^{+} / \mathrm{H}^{+}$exchanger and reversed the $\mathrm{Na}^{+} / \mathrm{Ca}^{2+}$ exchanger, while in high concentrations, Epigallocatechin-3-Gallate activated the $\beta 2$-adrenergic receptors. Thus, low doses of Epigallocatechin-3-Gallate offered cardio protection, and high doses of Epigallocatechin-3-Gallate raised the incidences of arrhythmia and diastolic dysfunction. The $32-$ adrenergic receptor was shown to be active in the cardiac effects of Epigallocatechin-3-Gallate (50). Epigallocatechin3-Gallate administration was shown to be helpful in reducing the ion channel mutations related to irregular cardiac excitability phenotypes in a computer simulation. Computer simulations of action potentials reveal that $30 \mu \mathrm{M}$ of Epigallocatechin-3-Gallate minimized and inhibited phenotypic action potential abnormalities (51).

Citrus fruits contain hesperidin, a flavanone glycoside.
Hesperetin is the aglycone form of hesperidin. Its name is derived from the word 'hesperidium', which refers to citrus fruit (52). Numerous studies have shown the antiarrhythmic and cardioprotective effects of hesperidin. One study examined the beneficial effects of hesperidin on ischemic reperfusion injury in rats. Due to ischemia, tissue nitrite and anti-oxidant levels decrease, and the incidences of arrhythmia and apoptosis of myocytes increase. The administration of hesperidin in animals restored nitrite in the cardiac tissues, and decreased arrhythmias, apoptosis, and inflammation. Hesperidin also caused a decrement in lipid peroxidation, and restored levels of superoxide dismutase and catalase. Similarly, a decrease in TNF- $\alpha$ and myeloperoxidase levels was also observed. The treatment also resulted in a decrement in the time lapse and occurrence of arrhythmias (53). At concentrations of 30 molL-1 or greater, hesperetin raised the QRS interval and heart rate while decreasing the corrected QT interval and cardiac and aortic contractile forces. With an effective inhibitory concentration of 100 molL-1, hesperetin blocked rat and human $\mathrm{NaV} 1.5$ channels. Further, hesperidin prevented the slow inactivation phase of $\mathrm{I}_{\mathrm{Na}}(54)$. According to reports, hesperidin reduces cardiac necrosis (55). Protein kinase B (Akt) expression was improved in animals treated with hesperidin $(100 \mathrm{mg} / \mathrm{kg})$, while the apoptosis regulator (BAX/BCL2) market ratio declined substantially. Irrespective of hesperidin administration, electrocardiogram ECG improvements were reversed in groups 2 hours after carbon monoxide $\mathrm{CO}$ exposure. In general, hesperidin minimized the detrimental cardiac effects of $\mathrm{CO}$ toxicity in rats (55). Table 2 sets out the anti-arrhythmic effects of other flavonoids.

\section{The role of anti-oxidants in the management of angina and myocardial infarction}

Angina is the most prevalent symptom of ischemic heart failure, and seems to be the leading risk factor for mortality around the world. Angina pectoris is characterized as substernal chest pain, strain, or irritation that is intensified by aerobic endurance and/or emotional tension, and persists for more than 30 to 60 seconds, but is improved by resting and nitroglycerine (62). A few studies have shown the antianginal properties of flavonoids. The anti-anginal effects of Ethyl-7-hydroxyaceto-flavone (63) and rutin (along with theophylline) have also been evaluated (64).

Myocardial infarction develops as blood circulation to a section of the heart reduces or ceases, triggering damage 
Table 2 Anti-arrhythmic effects of flavonoids

\begin{tabular}{ll}
\hline Flavonoid & Mechanism \\
\hline Acacetin & Suppression of transient outward $\mathrm{K}^{+}$current (56) \\
Astragalus flavonoids & $\begin{array}{l}\text { Increased expression of the endoplasmic reticulum stress signaling pathway factor activating } \\
\text { transcription factor } 4 \text { (57) }\end{array}$ \\
Xanthohumol & Stabilization of triggered $\mathrm{Ca}^{2+}$ sparks and waves (58) \\
Pinocembrin & Decreased Bax/Bcl-2 ratios (59) \\
Ampelopsin & Inhibition of $\mathrm{Na}^{+}$and promotion of $\mathrm{K}^{+}$currents $(60)$ \\
Methylflavonolamine & Prevention of ischemia (61) \\
\hline
\end{tabular}

to the heart muscle. The most frequent symptoms of myocardial infarction include chest pain or stiffness that can spread to the arm, neck, spine, throat, or jaw. Various studies have sought to evaluate effects of flavonoid intake on the onset of myocardial infraction, and the beneficial role of flavonoids has been established. In one study, nutritional data were gathered using a questionnaire that had been verified for validity and replicability (65). The high consumption of anthocyanidins decreased the risk of myocardial infarction, even in alcoholics (65). Another study found an inverse relationship between flavanol and flavone intake and associated coronary mortality rates (66). A study conducted on a geriatric population also showed that flavonoids have a beneficial role in the prevention of myocardial infarction (67). Dietary flavonoids, such as quercetin, kaempferol, and myricetin, were shown to be substantially inversely related to fatal myocardial infarction (68). Flavonoids, such as chrysin, apigenin, and naringenin, increased post-ischemic responsive regeneration in the heart, which was correlated with reduced tissue injury extension. 5-methoxy flavone has been shown to have the same type of biological effects (69).

In one study, the total flavonoids of Abelmoschus Manibot were evaluated to examine whether they played a beneficial role against myocardial infarction. The results showed that total flavonoid administration resulted in a decrement in the levels of lactate dehydrogenase, downregulatedIL-6, IL$1 \beta$ and TNF- $\alpha$ production, and decreased the expression of NLRPR3 inflammasome (70). Epimedium flavonoids also had protective effects against myocardial infarction. The myocardial infarcted area in the rats was found to be decreased to a different degree, and the activity of serum creatine phosphokinase, lactate dehydrogenase, and lipid peroxidation were found to be decreased. Additionally, the activity of anti-oxidant enzyme superoxide dismutase was found to be increased. The lowering of the ST-T segment, which began within 5 minutes, persisted for more than 3 hours (71). The flavonoids extracted from propolis were found to improve cardiac function. The extract decreased the degree of cardiac fibrosis and downregulated fibrosisrelated factors, including collagen I, collagen III, matrix metalloproteinase-2, and 9 . The activation of silent information regulator 1 was found to be the leading cause behind these beneficial effects (72).

\section{The role of anti-oxidants in coagulation disorders}

Coagulation diseases are pathogenies that impair the clotting processes of the blood. Coagulation abnormalities include hemophilia, hypercoagulable states, Von Willebrand disease, and deep venous thrombosis. The loss of normal anti-coagulation mechanisms, whether due to genetic deficiency or serious external trauma, might lead to thrombosis, which in turn can predispose people to deep vein thrombosis, stroke, and heart attack (73). Flavonoidrich flavonoids may reduce the risk of the hyper-activation of platelets, the progression of CVDs, pain, and thrombosis. Flavonoids also reduce the risk of atherosclerosis and atherothrombotic diseases (74). Table 3 sets out the role of various flavonoids in blood-associated disorders.

\section{Conclusions}

This literature review summarized epidemiologic and mechanism-based studies that examined the benefits of flavonoids and polyphenol for the cardiovascular system and their role in lowering the likelihood of heart disease. The vascular endothelium is a central governor of vascular homeostasis. Endothelial dysfunction plays a key role in the pathophysiology and physiological manifestations of 
Table 3 Beneficial role of flavonoids in coagulation disorders

\begin{tabular}{ll}
\hline Flavonoid & Mechanism \\
\hline Nelumbo flavonoids & Inhibition of platelet activation, adhesion, and aggregation (75) \\
Quercetin & Inhibition of fibrin polymers formation and clot formation (76) \\
Hinokiflavone & Inhibition of IL-1 $\beta$ induced expression of tissue factor (77) \\
4', 5, 6, 7-tetramethoxyflavone & Regulation of reaction of factor XII, factor XI, factor IX, and factor VIII (78) \\
\hline
\end{tabular}

coronary heart disease. Platelet accumulation plays an important role in the etiology of acute coronary syndromes, such as cardiac arrhythmia and dysfunctional angina. Flavonoids are fairly soluble in physiological media and thus are a potential candidate for the possible management of cardiovascular and associated disorders. Notably, they are also non-toxic in nature. Alleviating the oxidative stress induced by reactive oxygen species using antioxidant-rich flavonoids could lower the chances of platelet hyperactivation, heart disease, discomfort, and fibrosis. Additionally, flavonoids could help to prevent endothelial dysfunction, which is implicated in the progression of coronary artery and vascular diseases.

\section{Acknowledgments}

Funding: This work was supported by National Science and Technology Major Special Project [2017ZX09301003].

\section{Footnote}

Reporting Checklist: The authors have completed the Narrative Review reporting checklist. Available at https:// dx.doi.org/10.21037/apm-21-1343

Conflicts of Interest: Both authors have completed the ICMJE uniform disclosure form (available at https://dx.doi. org/10.21037/apm-21-1343). The authors have no conflicts of interest to declare.

Ethical Statement: The authors are accountable for all aspects of the work in ensuring that questions related to the accuracy or integrity of any part of the work are appropriately investigated and resolved.

Open Access Statement: This is an Open Access article distributed in accordance with the Creative Commons Attribution-NonCommercial-NoDerivs 4.0 International License (CC BY-NC-ND 4.0), which permits the non- commercial replication and distribution of the article with the strict proviso that no changes or edits are made and the original work is properly cited (including links to both the formal publication through the relevant DOI and the license). See: https://creativecommons.org/licenses/by-nc-nd/4.0/.

\section{References}

1. World Health Organization. Global Action Plan on Physical Activity 2018-2030: More Active People for a Healthier World. World Health Organization; 2019.

2. Singh BN. Morbidity and mortality in cardiovascular disorders: impact of reduced heart rate. J Cardiovasc Pharmacol Ther 2001;6:313-31.

3. Shah MS, Brownlee M. Molecular and Cellular Mechanisms of Cardiovascular Disorders in Diabetes. Circ Res 2016;118:1808-29.

4. WHO CVD Risk Chart Working Group. World Health Organization cardiovascular disease risk charts: revised models to estimate risk in 21 global regions. Lancet Glob Health 2019;7:e1332-45.

5. Maron BJ, Rowin EJ, Maron MS. Global Burden of Hypertrophic Cardiomyopathy. JACC Heart Fail 2018;6:376-8.

6. McKenna WJ, Maron BJ, Thiene G. Classification, Epidemiology, and Global Burden of Cardiomyopathies. Circ Res 2017;121:722-30.

7. Xu H, Deng K, Lin Z, et al. The effects of physical activity and sedentary behavior in the associations between cardiovascular diseases and depression: A four-way decomposition. J Affect Disord 2020;275:194-201.

8. Masiero M, Riva S, Oliveri S, et al. Optimistic bias in young adults for cancer, cardiovascular and respiratory diseases: A pilot study on smokers and drinkers. J Health Psychol 2018;23:645-56.

9. Astrup A, Magkos F, Bier DM, et al. Saturated Fats and Health: A Reassessment and Proposal for Food-Based Recommendations: JACC State-of-the-Art Review. J Am Coll Cardiol 2020;76:844-57. 
10. Islam MA, Amin MN, Siddiqui SA, et al. Trans fatty acids and lipid profile: A serious risk factor to cardiovascular disease, cancer and diabetes. Diabetes Metab Syndr 2019;13:1643-7.

11. Rehm J, Roerecke M. Cardiovascular effects of alcohol consumption. Trends Cardiovasc Med 2017;27:534-8.

12. Goel S, Sharma A, Garg A. Effect of Alcohol Consumption on Cardiovascular Health. Curr Cardiol Rep 2018;20:19.

13. Csige I, Ujvárosy D, Szabó Z, et al. The Impact of Obesity on the Cardiovascular System. J Diabetes Res 2018;2018:3407306.

14. Taverne YJ, Merkus D, Bogers AJ, et al. Reactive Oxygen Species: Radical Factors in the Evolution of Animal Life: A molecular timescale from Earth's earliest history to the rise of complex life. Bioessays 2018. doi: 10.1002/ bies.201700158.

15. He L, He T, Farrar S, et al. Antioxidants Maintain Cellular Redox Homeostasis by Elimination of Reactive Oxygen Species. Cell Physiol Biochem 2017;44:532-53.

16. Farías JG, Molina VM, Carrasco RA, et al. Antioxidant Therapeutic Strategies for Cardiovascular Conditions Associated with Oxidative Stress. Nutrients 2017;9:966.

17. Kim Y, Je Y. Flavonoid intake and mortality from cardiovascular disease and all causes: A meta-analysis of prospective cohort studies. Clin Nutr ESPEN 2017;20:68-77.

18. Bhatla SC. Secondary metabolites. In: Plant Physiology, Development and Metabolism. Springer, 2018:1099-166.

19. Fusi F, Trezza A, Tramaglino M, et al. The beneficial health effects of flavonoids on the cardiovascular system: Focus on K+ channels. Pharmacol Res 2020;152:104625.

20. Kesarkar S, Bhandage A, Deshmukh S, et al. Flavonoids: An Overview. J Pharm Res 2009;2:1148-54.

21. Olaleye MT, Crown OO, Akinmoladun AC, et al. Rutin and quercetin show greater efficacy than nifedipin in ameliorating hemodynamic, redox, and metabolite imbalances in sodium chloride-induced hypertensive rats. Hum Exp Toxicol 2014;33:602-8.

22. Mendes-Junior Ld, Monteiro MM, Carvalho Ados S, et al. Oral supplementation with the rutin improves cardiovagal baroreflex sensitivity and vascular reactivity in hypertensive rats. Appl Physiol Nutr Metab 2013;38:1099-106.

23. Kaur S, Muthuraman A. Therapeutic evaluation of rutin in two-kidney one-clip model of renovascular hypertension in rat. Life Sci 2016;150:89-94.

24. Edwards RL, Lyon T, Litwin SE, et al. Quercetin reduces blood pressure in hypertensive subjects. J Nutr 2007;137:2405-11.
25. Musial C, Kuban-Jankowska A, Gorska-Ponikowska M. Beneficial Properties of Green Tea Catechins. Int J Mol Sci 2020;21:1744.

26. Pastoriza S, Mesías M, Cabrera C, et al. Healthy properties of green and white teas: an update. Food Funct 2017;8:2650-62.

27. Xu R, Yang K, Ding J, et al. Effect of green tea supplementation on blood pressure: A systematic review and meta-analysis of randomized controlled trials. Medicine (Baltimore) 2020;99:e19047.

28. Jaffri JM, Mohamed S, Rohimi N, et al. Antihypertensive and cardiovascular effects of catechin-rich oil palm (Elaeis guineensis) leaf extract in nitric oxide-deficient rats. J Med Food 2011;14:775-83.

29. Kurita I, Maeda-Yamamoto M, Tachibana H, et al. Antihypertensive effect of Benifuuki tea containing O-methylated EGCG. J Agric Food Chem 2010;58:1903-8.

30. Huang R, Zhang Y, Shen S, et al. Antioxidant and pancreatic lipase inhibitory effects of flavonoids from different citrus peel extracts: An in vitro study. Food Chem 2020;326:126785.

31. Yamamoto M, Suzuki A, Hase T. Short-term effects of glucosyl hesperidin and hesperetin on blood pressure and vascular endothelial function in spontaneously hypertensive rats. J Nutr Sci Vitaminol (Tokyo) 2008;54:95-8.

32. Si H, Liu D. Genistein, a soy phytoestrogen, upregulates the expression of human endothelial nitric oxide synthase and lowers blood pressure in spontaneously hypertensive rats. J Nutr 2008;138:297-304.

33. Cho TM, Peng N, Clark JT, et al. Genistein attenuates the hypertensive effects of dietary $\mathrm{NaCl}$ in hypertensive male rats. Endocrinology 2007;148:5396-402.

34. Hodgson J, Croft K. Dietary flavonoids: Effects on endothelial function and blood pressure. J Sci Food Agricul 2006;86:2492-8.

35. Nachvak SM, Moradi S, Anjom-Shoae J, et al. Soy, Soy Isoflavones, and Protein Intake in Relation to Mortality from All Causes, Cancers, and Cardiovascular Diseases: A Systematic Review and Dose-Response Meta-Analysis of Prospective Cohort Studies. J Acad Nutr Diet 2019;119:1483-1500.e17.

36. Kuriyama S, Morio Y, Toba M, et al. Genistein attenuates hypoxic pulmonary hypertension via enhanced nitric oxide signaling and the erythropoietin system. Am J Physiol Lung Cell Mol Physiol 2014;306:L996-L1005.

37. Zhu ZY, Gao T, Huang Y, et al. Apigenin ameliorates hypertension-induced cardiac hypertrophy and downregulates cardiac hypoxia inducible factor-l $\alpha$ in rats. Food 
Funct 2016;7:1992-8.

38. Lagunas-Herrera H, Tortoriello J, Herrera-Ruiz M, et al. Acute and Chronic Antihypertensive Effect of Fractions, Tiliroside and Scopoletin from Malva parviflora. Biol Pharm Bull 2019;42:18-25.

39. Parichatikanond W, Pinthong D, Mangmool S. Blockade of the renin-angiotensin system with delphinidin, cyanin, and quercetin. Planta Med 2012;78:1626-32.

40. Martin D, Song J, Mark C, et al. Understanding the cardiovascular actions of soy isoflavones: potential novel targets for antihypertensive drug development. Cardiovasc Hematol Disord Drug Targets 2008;8:297-312.

41. Arutyunyan TV, Korystova AF, Kublik LN, et al. Effects of taxifolin on the activity of angiotensin-converting enzyme and reactive oxygen and nitrogen species in the aorta of aging rats and rats treated with the nitric oxide synthase inhibitor and dexamethasone. Age (Dordr) 2013;35:2089-97.

42. Leung LK, Su Y, Chen R, et al. Theaflavins in black tea and catechins in green tea are equally effective antioxidants. J Nutr 2001;131:2248-51.

43. Dreiseitel A, Korte G, Schreier P, et al. sPhospholipase $\mathrm{A}(2)$ is inhibited by anthocyanidins. J Neural Transm (Vienna) 2009;116:1071-7.

44. Malishevskaia IV, Ilashchuk TA, Okipniak IV. Therapeutic efficacy of quercetin in patients with is ischemic heart disease with underlying metabolic syndrome. Georgian Med News 2013;(225):67-71.

45. Chekalina NI, Shut SV, Trybrat TA, et al. Effect of quercetin on parameters of central hemodynamics and myocardial ischemia in patients with stable coronary heart disease. Wiad Lek 2017;70:707-11.

46. Ma Y, Wang Y, Gao Y, et al. Total flavonoids from Ganshanbian (Herba Hyperici Attenuati) effect the expression of CaL-alpha1C and K(ATP)-Kir6.1 mRNA of the myocardial cell membrane in myocardial ischemia-reperfusion arrhythmia rats. J Tradit Chin Med 2014;34:357-61.

47. Wu JX, Yu GR, Wang BY, et al. Effects of Viscum coloratum flavonoids on fast response action potentials of hearts. Zhongguo Yao Li Xue Bao 1994;15:169-72.

48. Wen-Feng C, Guo-Fen Q, Yan-Jie L, et al. Flavonoids from Chinese Viscum coloratum: antiarrhythmic efficacy and ionic mechanisms. Phytother Res 2006;20:1100-2.

49. Teramoto M, Muraki I, Yamagishi K, et al. Green Tea and Coffee Consumption and All-Cause Mortality Among Persons With and Without Stroke or Myocardial Infarction. Stroke 2021;52:957-65.
50. Bao L, Lu F, Chen H, et al. High concentration of epigallocatechin-3-gallate increased the incidences of arrhythmia and diastolic dysfunction via $\beta 2$-adrenoceptor. J Food Sci 2015;80:T659-63.

51. Boukhabza M, El Hilaly J, Attiya N, et al. In Silico Evaluation of the Potential Antiarrhythmic Effect of Epigallocatechin-3-Gallate on Cardiac Channelopathies. Comput Math Methods Med 2016;2016:7861653.

52. Ganeshurkar A, Saluja AK. The Pharmacological Potential of Hesperidin. Indian J Biochem Biophys 2019;56:287-300.

53. Gandhi C, Upaganalawar A, Balaraman R. Protection against in vivo focal myocardial ischemia/reperfusion injury-induced arrhythmias and apoptosis by hesperidin. Free Radic Res 2009;43:817-27.

54. Alvarez-Collazo J, López-Requena A, Galán L, et al. The citrus flavanone hesperetin preferentially inhibits slow-inactivating currents of a long QT syndrome type 3 syndrome $\mathrm{Na}+$ channel mutation. Br J Pharmacol 2019;176:1090-105.

55. Rezaee R, Sheidary A, Jangjoo S, et al. Cardioprotective effects of hesperidin on carbon monoxide poisoned in rats. Drug Chem Toxicol 2019;1-6.

56. Li GR, Wang HB, Qin GW, et al. Acacetin, a natural flavone, selectively inhibits human atrial repolarization potassium currents and prevents atrial fibrillation in dogs. Circulation 2008;117:2449-57.

57. Liu H, Hurile B, Xiong Y, et al. Effects of total flavonids of astragalus on arrhythmia,endoplasmic reticulum stress in mice with viral myocarditis. Zhongguo Ying Yong Sheng Li Xue Za Zhi 2018;34:16-8.

58. Arnaiz-Cot JJ, Cleemann L, Morad M. Xanthohumol Modulates Calcium Signaling in Rat Ventricular Myocytes: Possible Antiarrhythmic Properties. J Pharmacol Exp Ther 2017;360:239-48.

59. Lungkaphin A, Pongchaidecha A, Palee S, et al. Pinocembrin reduces cardiac arrhythmia and infarct size in rats subjected to acute myocardial ischemia/reperfusion. Appl Physiol Nutr Metab 2015;40:1031-7.

60. Wang Y, Fu L, Wang L, et al. Electrophysiological study on the antiarrhythmic mechanism of ampelopsin in rats. Zhonghua Xin Xue Guan Bing Za Zhi 2014;42:675-9.

61. Wang MZ, Wan BS, Zhou EF. Central action of antiarrhythmic effect of methylflavonolamine hydrochloride. Zhongguo Yao Li Xue Bao 1987;8:513-6.

62. Ong P, Camici PG, Beltrame JF, et al. International standardization of diagnostic criteria for microvascular angina. Int J Cardiol 2018;250:16-20. 
63. Strausak A, Cottier P, Schmid A. Ethyl-7-hydroxyacetoflavone (recordil) in the therapy of angina pectoris and its effects on hemodynamics and renal function. Cardiologia 1959;34:138-46.

64. Hofer E. Combination of theophyllin and rutin in the therapy of angina pectoris. Ther Ggw 1956;95:61-3.

65. Tavani A, Spertini L, Bosetti C, et al. Intake of specific flavonoids and risk of acute myocardial infarction in Italy. Public Health Nutr 2006;9:369-74.

66. Rimm EB, Katan MB, Ascherio A, et al. Relation between intake of flavonoids and risk for coronary heart disease in male health professionals. Ann Intern Med 1996;125:384-9.

67. Hertog MG, Feskens EJ, Hollman PC, et al. Dietary antioxidant flavonoids and risk of coronary heart disease: the Zutphen Elderly Study. Lancet 1993;342:1007-11.

68. Geleijnse JM, Launer LJ, Van der Kuip DA, et al. Inverse association of tea and flavonoid intakes with incident myocardial infarction: the Rotterdam Study. Am J Clin Nutr 2002;75:880-6.

69. Testai L, Martelli A, Cristofaro M, et al. Cardioprotective effects of different flavonoids against myocardial ischaemia/reperfusion injury in Langendorff-perfused rat hearts. J Pharm Pharmacol 2013;65:750-6.

70. Lv D, Cheng X, Tang L, et al. The cardioprotective effect of total flavonoids on myocardial ischemia/reperfusion in rats. Biomed Pharmacother 2017;88:277-84.

71. Huang XL, Wang W, Zhou YW. Protective effect of epimedium flavonoids injection on experimental

Cite this article as: Chen Z, Zhang SL. The role of flavonoids in the prevention and management of cardiovascular complications: a narrative review. Ann Palliat Med 2021;10(7):8254-8263. doi: 10.21037/apm-21-1343 myocardial infarction rats. Zhongguo Zhong Xi Yi Jie He Za Zhi 2006;26:68-71.

72. Wang Q, Sui X, Sui DJ, et al. Flavonoid Extract from Propolis Inhibits Cardiac Fibrosis Triggered by Myocardial Infarction through Upregulation of SIRT1. Evid Based Complement Alternat Med 2018;2018:4957573.

73. Wendelboe AM, Raskob GE. Global Burden of Thrombosis: Epidemiologic Aspects. Circ Res 2016;118:1340-7.

74. Peluso MR. Flavonoids attenuate cardiovascular disease, inhibit phosphodiesterase, and modulate lipid homeostasis in adipose tissue and liver. Exp Biol Med (Maywood) 2006;231:1287-99.

75. Rajput MA, Khan RA, Zafar S, et al. Assessment of anticoagulant activity of Nelumbo nucifera fruit. Pak J Pharm Sci 2019;32:2561-4.

76. Choi JH, Kim KJ, Kim S. Comparative Effect of Quercetin and Quercetin-3-O- $\beta$-d-Glucoside on Fibrin Polymers, Blood Clots, and in Rodent Models. J Biochem Mol Toxicol 2016;30:548-58.

77. Lale A, Herbert JM, Augereau JM, et al. Ability of different flavonoids to inhibit the procoagulant activity of adherent human monocytes. J Nat Prod 1996;59:273-6.

78. Triratana T, Suwannuraks R, Naengchomnong W. Effect of Eupatorium odoratum on blood coagulation. J Med Assoc Thai 1991;74:283-7.

(English Language Editor: L. Huleatt) 